\title{
RESEARCH
}

Open Access

\section{High-flow nasal oxygenation reduces the risk of desaturation in adults receiving procedural sedation: a meta-analysis of randomized controlled trials}

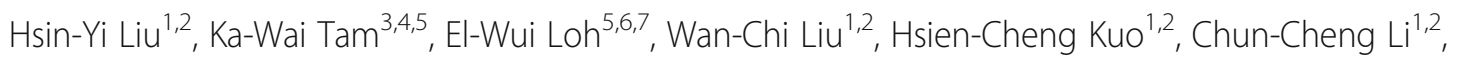
Yih-Giun Cherng ${ }^{1,2}$, Jui-Tai Chen ${ }^{1,2^{*}}$ and Ying-Hsuan Tai ${ }^{1,2^{*}}$ (D)

\begin{abstract}
Background: Procedural sedation reduces patients' discomfort and anxiety, facilitating performance of the examination and intervention. However, it may also cause adverse events, including airway obstruction and hypoxia. We conducted this systematic review and meta-analysis to evaluate the efficacy of high-flow nasal oxygenation (HFNO) compared with that of standard oxygen therapy in adult patients undergoing procedural sedation.

Methods: We identified randomized controlled trials published before November 2020 based on PubMed, Embase, and Cochrane Library databases and ClinicalTrials.gov registry. Intraprocedural desaturation [peripheral oxygen saturation $\left.\left(\mathrm{SpO}_{2}\right)<90 \%\right]$ was evaluated as the primary outcome. The secondary outcomes were the lowest $\mathrm{SpO}_{2}$, need for airway intervention, oxygen therapy-related complications, and patient, operator, and anesthetist's satisfaction.

Results: Six trials with a total of 2633 patients were reviewed. Patients using HFNO compared with standard oxygen therapy had a significantly lower risk of intraprocedural desaturation [risk ratio $0.18,95 \%$ confidence interval (Cl) 0.04-0.87]. The lowest intraprocedural $\mathrm{SpO}_{2}$ in $\mathrm{HFNO}$ group was significantly higher than that in standard oxygen therapy group (mean difference $4.19 \%, 95 \%$ Cl 1.74-6.65).
\end{abstract}

Conclusions: Compared with standard oxygen therapy, HFNO may reduce the risk of desaturation and increase the lowest $\mathrm{SpO}_{2}$ in adult patients undergoing sedation for medical procedures.

Keywords: Conscious sedation, High-flow nasal cannula, Hypoxia, Oxygen therapy, Patient satisfaction

\footnotetext{
*Correspondence: 19240@s.tmu.edu.tw; 18045@s.tmu.edu.tw

'Department of Anesthesiology, Shuang Ho Hospital, Taipei Medical

University, No. 291, Zhongzheng Rd., Zhonghe District, New Taipei City

23561, Taiwan

Full list of author information is available at the end of the article
}

(c) The Author(s). 2021 Open Access This article is licensed under a Creative Commons Attribution 4.0 International License, which permits use, sharing, adaptation, distribution and reproduction in any medium or format, as long as you give appropriate credit to the original author(s) and the source, provide a link to the Creative Commons licence, and indicate if changes were made. The images or other third party material in this article are included in the article's Creative Commons licence, unless indicated otherwise in a credit line to the material. If material is not included in the article's Creative Commons licence and your intended use is not permitted by statutory regulation or exceeds the permitted use, you will need to obtain permission directly from the copyright holder. To view a copy of this licence, visit http://creativecommons.org/licenses/by/4.0/. The Creative Commons Public Domain Dedication waiver (http://creativecommons.org/publicdomain/zero/1.0/) applies to the data made available in this article, unless otherwise stated in a credit line to the data. 


\section{Background}

Medical procedures cause anxiety, pain, and discomfort, such as gastrointestinal endoscopy, bronchoscopy, and dental treatment. These procedures are frequently performed with sedation to reduce patients' discomfort and apprehension, contributing to a better quality of examination or intervention (Meining et al. 2007). Anesthetics and analgesics used for sedation provide hemodynamic stability by attenuating the autonomic stress response (Gerstein et al. 2016). However, sedation itself may decrease respiratory drive, cause upper airway obstruction, and thereafter hypoxia during procedures (Mason et al. 2019; Amornyotin 2013). Severe hypoxia prompts airway intervention such as mask ventilation, thus interrupting the procedure. Prolonged hypoxia may lead to cardiopulmonary distress, bradycardia, permanent neurologic damage, and even death (Shirota et al. 2020; Xiao et al. 2016; Qadeer et al. 2011; Wehrmann and Riphaus 2008). Thus, it is crucial to prevent the occurrence of hypoxia while providing an adequate depth of sedation.

In procedural sedation, patients generally receive supplemental oxygen to reduce the risk of desaturation. Nasal cannulas and simple masks are conventionally recognized as standard oxygen therapy to deliver oxygen at a maximum of $15 \mathrm{~L} / \mathrm{min}$. Currently, high-flow nasal oxygen device produces heated and humidified oxygen and enables oxygen comfortably delivered at a rate up to 70 $\mathrm{L} / \mathrm{min}$ (Spoletini et al. 2015). Compared with standard oxygen therapy, high-flow nasal oxygenation (HFNO) allows for rapid carbon dioxide washout (i.e., dead space washout), maintains a constant fraction of inspired oxygen $\left(\mathrm{FiO}_{2}\right)$, produces a positive end-expiratory pressure, reduces respiratory effort, and improves patient comfort (Helviz and Einav 2018; Lee et al. 2016). A meta-analysis recently reported that HFNO may reduce hypoxia and increase minimum $\mathrm{O}_{2}$ saturation during intraoperative period (Spence et al. 2020). However, it remains unclear whether HFNO is more effective in preventing occurrence of desaturation in the setting of procedural sedation compared to standard oxygen therapy. Accordingly, we conducted a systematic review and meta-analysis to compare the efficacy of oxygenation between HFNO and standard oxygen therapy in patients undergoing procedural sedation.

\section{Methods}

\section{Criteria of study selection}

We included randomized controlled trials (RCTs) comparing HFNO and standard oxygen care in patients undergoing sedation for diagnostic or interventional procedures in which endotracheal intubation or a supraglottic device was not necessary. In the study selection, we adopted the definition of sedation and general anesthesia by the American Society of Anesthesiologists,
Committee on Quality Management and Departmental Administration 2019 (American Society of Anesthesiologists, Committee on Quality Management and Departmental Administration 2019). Specifically, sedation is a drug-induced depression of consciousness; patients are arousable and have a purposeful response to verbal, tactile, or painful stimulation (American Society of Anesthesiologists, Committee on Quality Management and Departmental Administration 2019). By contrast, patients under general anesthesia are unarousable even by painful stimulation and frequently have inadequate spontaneous ventilation, necessitating airway intervention (American Society of Anesthesiologists, Committee on Quality Management and Departmental Administration 2019). Studies were also required to clearly report the inclusion and exclusion criteria for patients, medical procedures, sedation techniques, and oxygenation strategy. Studies were excluded for the following reasons: (1) inclusion of pediatric patients, defined as younger than 18 years old, (2) inclusion of critically ill patients who had respiratory failure and required endotracheal intubation, and (3) comparison of respiratory support at the time of endotracheal extubation.

\section{Search strategy}

We searched relevant studies published before November 2020 from the PubMed, Embase, and Cochrane Library databases using the following Medical Subject Headings: (high-flow OR high flow nasal) AND (sedation). The "related articles" option in PubMed was used to broaden the search, and all abstracts, studies, and citations retrieved were reviewed. In addition, we identified other studies by using the reference sections of relevant papers and by corresponding with subject experts. Finally, unpublished studies were collected from the ClinicalTrials.gov registry (http://clinicaltrials.gov/). No language restriction was applied. The systematic review described herein has been accepted by PROSPERO, an online international prospective register of systematic reviews curated by the National Institute for Health Research (CRD42020203175).

\section{Data extraction}

Baseline and outcome data were independently retrieved by two reviewers (H.Y.L. and J.T.C.), who extracted the following data: study designs, patient characteristics, inclusion and exclusion criteria, medical procedures, sedation techniques, oxygenation strategy, intraprocedural desaturation events, lowest $\mathrm{O}_{2}$ saturation, need for airway intervention, patient, operator, and anesthetist satisfaction, and oxygen therapy-related complications. Decisions recorded individually by the reviewers were compared, and disagreements were resolved by a third 
reviewer (K.W.T.). The authors of the studies were contacted for additional information if needed.

\section{Appraisal of methodological quality}

Two reviewers (H.Y.L. and J.T.C.) independently assessed the methodological quality of each study by using the risk of bias method recommended by The Cochrane Collaboration (Higgins et al. 2011). The following domains were assessed: adequacy of randomization, allocation concealment, outcome assessor blinding to patient information, follow-up duration, information provided to participants regarding study withdrawal, whether intention-to-treat analysis was performed, and freedom from other biases.

\section{Outcomes of interest}

Primary outcome was the event of desaturation $\left(\mathrm{SpO}_{2}<\right.$ 90\%) during the procedure. Secondary outcomes were (1) the lowest $\mathrm{SpO}_{2}$, (2) need for airway intervention, including chin lift, jaw thrust, bag mask ventilation, insertion of a nasal or oral airway, and endotracheal intubation, (3) oxygen therapy-related complications, and (4) patient, operator, and anesthetist satisfaction.

\section{Statistical analyses}

Data were analyzed using Review Manager (version 5.3; The Cochrane Collaboration, Oxford, England, UK). Meta-analysis was performed following PRISMA guidelines (Moher et al. 2009). Mean and standard deviations (SD) were estimated from the provided median and interquartile range (IQR) (Luo et al. 2018; Shi et al. 2020). Dichotomous outcomes (desaturation event, need for airway intervention, and oxygen therapy-related complications) were presented as proportions or ratios and analyzed using risk ratios (RRs) as the summary statistic. The effect sizes of continuous outcomes were reported as the weighted mean difference (WMD) [95\% confidence interval $(\mathrm{CI})]$. A pooled estimate of the $\mathrm{RR}$ and WMD was computed using the DerSimonian and Laird random effect models (DerSimonian and Laird 1986).

Statistical heterogeneity and the inconsistency of treatment effects across studies were evaluated using Cochrane $Q$ test and $I^{2}$ statistics, respectively. Statistical significance was set at $p<0.10$ for Cochrane $Q$ test. Statistical heterogeneity across studies was assessed using the $I^{2}$ test, which quantifies the proportion of the

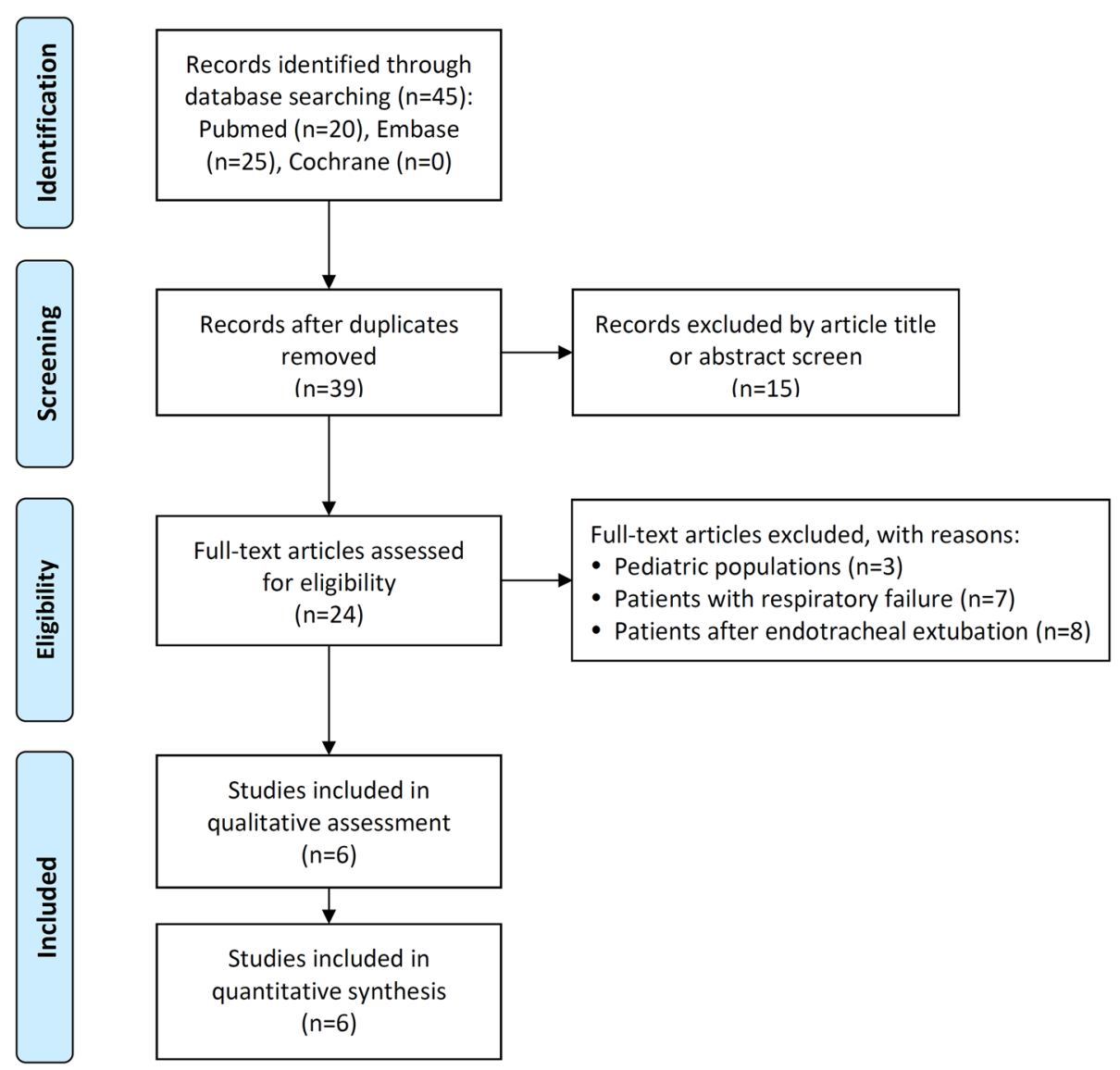

Fig. 1 Flowchart of study selection 
total outcome variability across the studies. Moreover, subgroup analyses were performed with obese and nonobese patients and eliminated the result of Riccio and colleagues due to their study population restricted to the obese (Riccio et al. 2019).

\section{Results}

\section{Trial characteristics}

Figure 1 illustrates the flowchart of trial screening and selection. The initial search yielded 90 citations, of which 66 were deemed ineligible based on title and abstract screening. Next, the full texts of 24 studies were retrieved. Most of them $(n=18)$ were excluded for the following reasons: 3 included pediatric populations; 7 focused on patients with respiratory failure; 8 evaluated patients following endotracheal extubation. Six studies were finally included for analysis (Riccio et al. 2019; Ben-Menachem et al. 2020; Douglas et al. 2018; Lin et al. 2019; Teng et al. 2019; Sago et al. 2015).

These six trials were published between 2015 and 2020, with sample sizes ranging from 30 to 1994. Two of them recruited patients for bronchoscopy (Ben-
Menachem et al. 2020; Douglas et al. 2018), two for upper gastrointestinal endoscopy (Lin et al. 2019; Teng et al. 2019), one for colonoscopy (Riccio et al. 2019), and one for dental treatment (Sago et al. 2015). One trial recruited patients with morbid obesity [mean body mass index (BMI) $48.5 \mathrm{~kg} / \mathrm{m}^{2}$ ) (Riccio et al. 2019) and five recruited patients with mean BMI $<28 \mathrm{~kg} / \mathrm{m}^{2}$ (Ben-Menachem et al. 2020; Douglas et al. 2018; Lin et al. 2019; Teng et al. 2019; Sago et al. 2015). For the HFNO group, all trials set the flow rate at $30-70 \mathrm{~L} / \mathrm{min} ; \mathrm{FiO}_{2}$ was $100 \%$ in three trials (Douglas et al. 2018; Lin et al. 2019; Teng et al. 2019), 36 to $40 \%$ in two trials (Riccio et al. 2019; Sago et al. 2015), and not mentioned in one trial (Ben-Menachem et al. 2020). For the standard oxygen therapy group, all trials set the flow rate at 2 to $10 \mathrm{~L} /$ min; the oxygen was delivered through a nasal cannula in five trials (Riccio et al. 2019; Ben-Menachem et al. 2020; Lin et al. 2019; Teng et al. 2019; Sago et al. 2015) and through bite block in one (Douglas et al. 2018). Sago and colleagues divided the HFNO group into two with respect to the flow rate $(30 \mathrm{~L} / \mathrm{min}$ and $50 \mathrm{~L} / \mathrm{min})$ and compared them separately with the standard oxygen

Table 1 Characteristics of the selected randomized controlled trials

\begin{tabular}{|c|c|c|c|c|c|c|}
\hline $\begin{array}{l}\text { Authors } \\
\text { (year) }\end{array}$ & $\begin{array}{l}\text { Inclusion } \\
\text { criteria }\end{array}$ & $\begin{array}{l}\text { No. of } \\
\text { patients } \\
\text { (male, \%) }\end{array}$ & $\begin{array}{l}\text { Age, } \\
\text { years } \\
\text { [mean } \\
(S D)]\end{array}$ & $\begin{array}{l}\text { BMI } \\
\text { [mean } \\
\text { (SD)] }\end{array}$ & Sedation technique and level of sedation & Oxygenation strategy \\
\hline $\begin{array}{l}\text { Riccio et al. } \\
(2019)\end{array}$ & $\begin{array}{l}\text { BMI > } 40 \text { for } \\
\text { elective } \\
\text { colonoscopy }\end{array}$ & $\begin{array}{l}\mathrm{H}: 28(14) \\
\text { S: } 31(13)\end{array}$ & $\begin{array}{l}\mathrm{H}: 54(8) \\
\text { S: } 59(7)\end{array}$ & $\begin{array}{l}\mathrm{H}: 48 \\
(7) \\
\mathrm{S}: 49 \\
(10)\end{array}$ & $\begin{array}{l}\text { Induction with lidocaine up to } 100 \mathrm{mg}+\text { propofol 30- } \\
100 \mathrm{mg} \text {. Maintenance with propofol } 120-150 \mu \mathrm{g} / \mathrm{kg} / \\
\text { min ideal body weight. Keep RASS }-3 \text { to }-4\end{array}$ & $\begin{array}{l}\mathrm{H}: \mathrm{FiO}_{2} 36-40 \% \text {, up to } 60 \\
\mathrm{~L} / \mathrm{min} \\
\mathrm{S}: \mathrm{FiO}_{2} 36-40 \%, 4 \mathrm{~L} / \mathrm{min} \\
\text { via } \mathrm{N} / \mathrm{C}\end{array}$ \\
\hline $\begin{array}{l}\text { Ben- } \\
\text { Menachem } \\
\text { et al. (2020) }\end{array}$ & $\begin{array}{l}\text { Age } \geq 18 \text {, lung } \\
\text { transplant } \\
\text { recipients, for } \\
\text { TBLB }\end{array}$ & $\begin{array}{l}H: 37(60) \\
\text { S: } 39(74)\end{array}$ & $\begin{array}{l}H: 55 \\
(12) \\
\text { S: } 56(12)\end{array}$ & $\begin{array}{l}\mathrm{H}: 25 \\
(4) \\
\text { S: } 25 \\
(4)\end{array}$ & $\begin{array}{l}\text { Premedication with midazolam } 1-3 \mathrm{mg} \text {. } \\
\text { Induction and maintenance with propofol and } \\
\text { alfentanil. }\end{array}$ & $\begin{array}{l}\mathrm{H}: 30-50 \mathrm{~L} / \mathrm{min} \\
\mathrm{S}: 4-10 \mathrm{~L} / \mathrm{min} \text { via N/C }\end{array}$ \\
\hline $\begin{array}{l}\text { Douglas } \\
\text { et al. (2018) }\end{array}$ & $\begin{array}{l}\text { Age } \geq 18, \text { for } \\
\text { endobronchial } \\
\text { ultrasound }\end{array}$ & $\begin{array}{l}H: 30(63) \\
\text { S: } 30(63)\end{array}$ & $\begin{array}{l}H: 63 \\
(14) \\
\text { S: } 63(14)\end{array}$ & $\begin{array}{l}\mathrm{H}: 27 \\
(6) \\
\text { S: } 27 \\
(6)\end{array}$ & $\begin{array}{l}\text { Induction and maintenance with midazolam, opioids, } \\
\text { and/or propofol. } \\
\text { Keep MOAA/S equal to } 4 \text {. }\end{array}$ & $\begin{array}{l}\mathrm{H}: \mathrm{FiO}_{2} 100 \% \text {, start with } \\
30 \mathrm{~L} / \mathrm{min} \text {, then } 30-70 \mathrm{~L} / \\
\text { min after sedation } \\
\mathrm{S}: 10-15 \mathrm{~L} / \mathrm{min} \text { via a bite } \\
\text { block }\end{array}$ \\
\hline $\begin{array}{l}\text { Lin et al. } \\
(2019)\end{array}$ & $\begin{array}{l}\text { Outpatients for } \\
\text { elective } \\
\text { gastroscopy }\end{array}$ & $\begin{array}{l}\text { H: } 994 \\
(42) \\
\text { S: } 1000 \\
(41)\end{array}$ & $\begin{array}{l}\mathrm{H}: 48 \\
(19) \\
\text { S: } 47(19)\end{array}$ & $\begin{array}{l}\mathrm{H}: 23 \\
(3) \\
\text { S: } 23 \\
(3)\end{array}$ & $\begin{array}{l}\text { Induction and maintenance with intermittent boluses of } \\
\text { propofol } 0.5 \mathrm{mg} / \mathrm{kg} \text {. } \\
\text { Keep RSS > } 4\end{array}$ & $\begin{array}{l}\mathrm{H} \text { : start with } 2 \mathrm{~L} / \mathrm{min} \text { via } \\
\mathrm{N} / \mathrm{C} \text {, then } \mathrm{FiO}_{2} 100 \%, 60 \\
\mathrm{~L} / \mathrm{min} \text { after sedation } \\
\mathrm{S}: 2 \mathrm{~L} / \mathrm{min} \text { via } \mathrm{N} / \mathrm{C}\end{array}$ \\
\hline $\begin{array}{l}\text { Teng et al. } \\
\text { (2019) }\end{array}$ & $\begin{array}{l}\text { Age } 20-80, \text { ASA } \\
\text { class I or II, for } \\
\text { outpatient EGD }\end{array}$ & $\begin{array}{l}H: 50(38) \\
M: 51(37) \\
\text { S: } 51(43)\end{array}$ & $\begin{array}{l}H: 47 \\
(15) \\
M: 51 \\
(12) \\
\text { S: } 52(13)\end{array}$ & $\begin{array}{l}\mathrm{H}: 23 \\
(4) \\
\mathrm{M}: 23 \\
(4) \\
\text { S: } 23 \\
(4)\end{array}$ & $\begin{array}{l}\text { Induction with midazolam } 0.05 \text { mg/kg }+ \text { alfentanil } 0.2 \\
\mu \mathrm{g} / \mathrm{kg} \text {. Maintenance with TCl of propofol. } \\
\text { Keep MOAA/S }<2 \text {. }\end{array}$ & $\begin{array}{l}\mathrm{H}: \mathrm{FiO}_{2} 100 \%, 30 \mathrm{~L} / \mathrm{min} \\
\mathrm{M}: 5 \mathrm{~L} / \mathrm{min} \text { direct to nose } \\
\text { and mouth } \\
\mathrm{S}: 5 \mathrm{~L} / \mathrm{min} \text { via N/C }\end{array}$ \\
\hline $\begin{array}{l}\text { Sago et al. } \\
(2015)\end{array}$ & $\begin{array}{l}\text { For dental } \\
\text { treatment under } \\
\text { sedation }\end{array}$ & $\begin{array}{l}\mathrm{H} 1: 10 \\
\text { (NR) } \\
\mathrm{H} 2: 10 \\
\text { (NR) } \\
\text { S: } 10 \text { (NR) }\end{array}$ & $\begin{array}{l}\text { H1: } 37 \\
(12) \\
\text { H2: } 39 \\
(11) \\
\text { S: } 40(15)\end{array}$ & $\begin{array}{l}\text { H1: } 22 \\
(3) \\
\text { H2: } 22 \\
(3) \\
\text { S: } 23 \\
(3)\end{array}$ & $\begin{array}{l}\text { Induction with midazolam } 0.05 \mathrm{mg} / \mathrm{kg}+\mathrm{TCl} \text { of } \\
\text { propofol. Maintenance with TCl of propofol, plasma } \\
\text { concentration } 1.2-2 \mu \mathrm{g} / \mathrm{mL} \text {. Keep bispectral index } 70 \text {. }\end{array}$ & $\begin{array}{l}\mathrm{H} 1: \mathrm{FiO}_{2} 40 \%, 30 \mathrm{~L} / \mathrm{min} \\
\mathrm{H} 2: \mathrm{FiO}_{2} 40 \%, 50 \mathrm{~L} / \mathrm{min} \\
\mathrm{S}: 5 \mathrm{~L} / \mathrm{min} \text { via } \mathrm{N} / \mathrm{C}\end{array}$ \\
\hline
\end{tabular}

Abbreviations: ASA American Society of Anesthesiologists, $B M I$ body mass index, $E G D$ esophagogastroduodenoscopy, FiO $_{2}$ fraction of inspired oxygen, $\mathrm{H}$ high-flow nasal oxygenation, $M$ mandibular advancement device, MOAA/S Modified Observer's Assessment of Alertness/Sedation Scale, N/C nasal cannula, NR not reported, RASS Richmond Agitation-Sedation Scale, RSS Ramsay Sedation Scale, S standard oxygen therapy, TBLB transbronchial lung biopsy, TCI, target continuous infusion 
therapy group (Sago et al. 2015). We combined the two HFNO groups in our analysis. Two trials used propofol as the sedative agents (Riccio et al. 2019; Lin et al. 2019); one used propofol with midazolam (Sago et al. 2015); two used propofol with midazolam and alfentanil (BenMenachem et al. 2020; Teng et al. 2019); one used midazolam, opioids, and/or propofol at the anesthetist's discretion (Douglas et al. 2018). Baseline patient characteristics were balanced between HFNO group and standard oxygen therapy group in all included trials (Table 1).

Table 2 summarizes the methodological quality of the included trials. All studies had acceptable methods of randomization. Three used intention-to-treat analysis (Riccio et al. 2019; Douglas et al. 2018; Sago et al. 2015), and the other three used per-protocol analysis (BenMenachem et al. 2020; Lin et al. 2019; Teng et al. 2019). The proportion of patients lost to follow-up was acceptable $(<20 \%)$ in all trials. Participants were not blinded in any trial owing to the study design.

\section{Desaturation event}

Five trials compared intraprocedural desaturation events between HFNO and standard oxygen therapy (Riccio et al. 2019; Ben-Menachem et al. 2020; Douglas et al. 2018; Lin et al. 2019; Teng et al. 2019). Four trials defined desaturation or hypoxic events as $\mathrm{SpO}_{2}<90 \%$ (Riccio et al. 2019; Ben-Menachem et al. 2020; Douglas et al. 2018; Teng et al. 2019). Lin and co-workers categorized low- $\mathrm{SpO}_{2}$ events into subclinical respiratory depression $\left(\mathrm{SpO}_{2}, 90\right.$ to $\left.94 \%\right)$, hypoxia $\left(\mathrm{SpO}_{2}, 75\right.$ to $89 \%$ for $<60 \mathrm{~s})$, and severe hypoxia $\left(\mathrm{SpO}_{2},<75 \%\right.$ or 75 to $89 \%$ for $>60$ s) (Lin et al. 2019). For this study (Lin et al. 2019), we considered hypoxic and severe hypoxic events as desaturation events in the data synthesis. HFNO was associated with a significantly lower risk of intraprocedural desaturation (RR, 0.18, 95\% CI, 0.04-0.87) compared with standard oxygen therapy (Fig. 2). Subgroup analysis revealed that the reduced risk of HFNO was augmented for nonobese patients (RR, 0.11, 95\% CI, 0.02-0.65).

\section{Lowest $\mathrm{SpO}_{2}$}

Four trials compared the intraprocedural lowest $\mathrm{SpO}_{2}$ between HFNO and standard oxygen therapy (Riccio et al. 2019; Ben-Menachem et al. 2020; Douglas et al. 2018; Sago et al. 2015). Two reported the data as mean and SD (Riccio et al. 2019; Sago et al. 2015), and two as median and IQR (Ben-Menachem et al. 2020; Douglas et al. 2018). Therefore, mean and SD were estimated from the provided median and IQR (Luo et al. 2018; Shi et al. 2020). Sago and colleagues presented the values as a figure of mean and SD, and the statistic number was estimated from the scale on the figure (Sago et al. 2015). The intraprocedural lowest $\mathrm{SpO}_{2}$ of HFNO group was significantly higher than that of standard oxygen therapy group (WMD, 4.19\%, 95\% CI, 1.74-6.65) (Fig. 3). Subgroup analysis showed a larger difference (WMD, 4.99\%, 95\% CI, 2.34-7.63) between groups for nonobese patients.

\section{Need for airway intervention}

Five trials compared the incidence of airway intervention between HFNO and standard oxygen therapy (Riccio et al. 2019; Ben-Menachem et al. 2020; Lin et al. 2019; Teng et al. 2019; Sago et al. 2015). Timing of airway intervention was set at $\mathrm{SpO}_{2}<94 \%$ or obvious airway obstruction (Ben-Menachem et al. 2020), $\mathrm{SpO}_{2}<95 \%{ }^{21}$, $\mathrm{SpO}_{2}<90 \%{ }^{19}, \mathrm{SpO}_{2}<95 \%$ for $>1 \mathrm{~min}^{24}$, and not mentioned in two trials (Ben-Menachem et al. 2020; Teng et al. 2019). Four trials reported the number of patients who received airway intervention (Riccio et al. 2019; Lin et al. 2019; Teng et al. 2019; Sago et al. 2015), and one reported the number of interventions for each patient (Ben-Menachem et al. 2020). The result of BenMenachem and colleagues was not comparable and was

Table 2 Methodological quality assessment of the included trials

\begin{tabular}{|c|c|c|c|c|c|c|}
\hline Authors (year) & $\begin{array}{l}\text { Bias from } \\
\text { randomization } \\
\text { process }\end{array}$ & $\begin{array}{l}\text { Deviations from } \\
\text { intended interventions }\end{array}$ & $\begin{array}{l}\text { Bias caused by } \\
\text { missing outcome } \\
\text { data }\end{array}$ & $\begin{array}{l}\text { Bias in outcome } \\
\text { measurement }\end{array}$ & $\begin{array}{l}\text { Bias in selection of } \\
\text { reported results }\end{array}$ & $\begin{array}{l}\text { Overall } \\
\text { risk of } \\
\text { bias }\end{array}$ \\
\hline $\begin{array}{l}\text { Riccio et al. } \\
(2019)\end{array}$ & Low risk & Some concerns & Low risk & Low risk & Low risk & $\begin{array}{l}\text { Some } \\
\text { concerns }\end{array}$ \\
\hline $\begin{array}{l}\text { Ben-Menachem } \\
\text { et al. (2020) }\end{array}$ & Low risk & Some concerns & Low risk & Low risk & Low risk & $\begin{array}{l}\text { Some } \\
\text { concerns }\end{array}$ \\
\hline $\begin{array}{l}\text { Douglas et al. } \\
\text { (2018) }\end{array}$ & Low risk & Some concerns & Low risk & Low risk & Low risk & $\begin{array}{l}\text { Some } \\
\text { concerns }\end{array}$ \\
\hline Lin et al. (2019) & Low risk & Low risk & Low risk & Low risk & Low risk & Low risk \\
\hline $\begin{array}{l}\text { Teng et al. } \\
\text { (2019) }\end{array}$ & Some concerns & Low risk & Low risk & Low risk & Low risk & $\begin{array}{l}\text { Some } \\
\text { concerns }\end{array}$ \\
\hline $\begin{array}{l}\text { Sago et al. } \\
(2015)\end{array}$ & Some concerns & Some sconcerns & Low risk & Low risk & Low risk & $\begin{array}{l}\text { Some } \\
\text { concerns }\end{array}$ \\
\hline
\end{tabular}




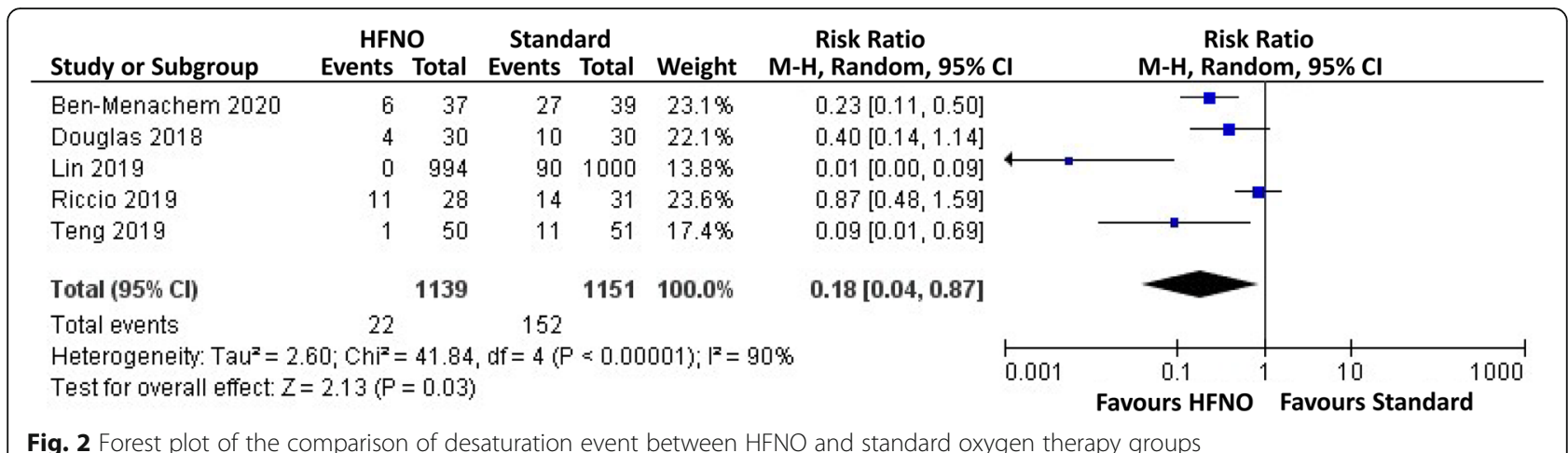

thus excluded from our meta-analysis (Ben-Menachem et al. 2020). There was no significant difference in the risk of airway intervention between groups ( $R R, 0.18$, 95\% CI, 0.01-2.52) (Fig. 4). Subgroup analysis revealed that HFNO was linked to a lower risk of airway intervention compared to standard oxygen therapy in nonobese patients (RR, 0.09, 95\% CI, 0.02-0.36).

\section{Complications}

Three trials evaluated oxygen therapy-related complications (Douglas et al. 2018; Lin et al. 2019; Teng et al. 2019). No complication was reported in either group in one trial (Douglas et al. 2018). Lin and co-workers reported that 17 patients in the HFNO group experienced dry nasal mucosa or nasal pain and provided no description of complications in the standard oxygen therapy group (Lin et al. 2019). Teng and colleagues reported that 2 patients had nasal dryness and itching in the standard oxygen therapy group and none in the HFNO group (Teng et al. 2019). Considering the inconsistent evaluation of related complications in these trials, we did not compare oxygen therapy-related complications between groups.

\section{Satisfaction of patients, operators, and anesthetists}

Three trials compared patient satisfaction between HFNO and standard oxygen therapy (Ben-Menachem et al. 2020; Douglas et al. 2018; Sago et al. 2015), and no significant difference was noted between groups (WMD, $-0.02,95 \% \mathrm{CI},-0.19$ to 0.14 ).

Three trials compared operator satisfaction between HFNO and standard oxygen therapy (Ben-Menachem et al. 2020; Douglas et al. 2018; Sago et al. 2015). Satisfaction was measured using a 5-point scale ranging from 1 (very dissatisfied) to 5 (very satisfied) in two trials (Ben-Menachem et al. 2020; Sago et al. 2015). One trial used the rating in opposite directions (Douglas et al. 2018), and the results were converted into the same direction as those of the other two trials. No significant difference was observed in operator satisfaction between groups (WMD, 0.11, 95\% CI, -0.25 to 0.46 ).

Two trials compared anesthetist satisfaction between HFNO and standard oxygen therapy (Ben-Menachem et al. 2020; Douglas et al. 2018). One trial demonstrated that HFNO had significantly better anesthetist satisfaction than standard oxygen therapy (4-5 vs. 2-4, $p<$ 0.001) (Ben-Menachem et al. 2020). However, another study observed no difference between groups ( $p=0.28$ ) (Douglas et al. 2018). Meta-analysis showed no significant difference in anesthetist satisfaction between groups (WMD, 1.0, 95\% CI, -0.76 to 2.76 ).

\section{Discussion}

Our analysis showed that HFNO was associated with a reduced risk of desaturation compared to standard oxygen therapy in procedural sedation. In addition, patients

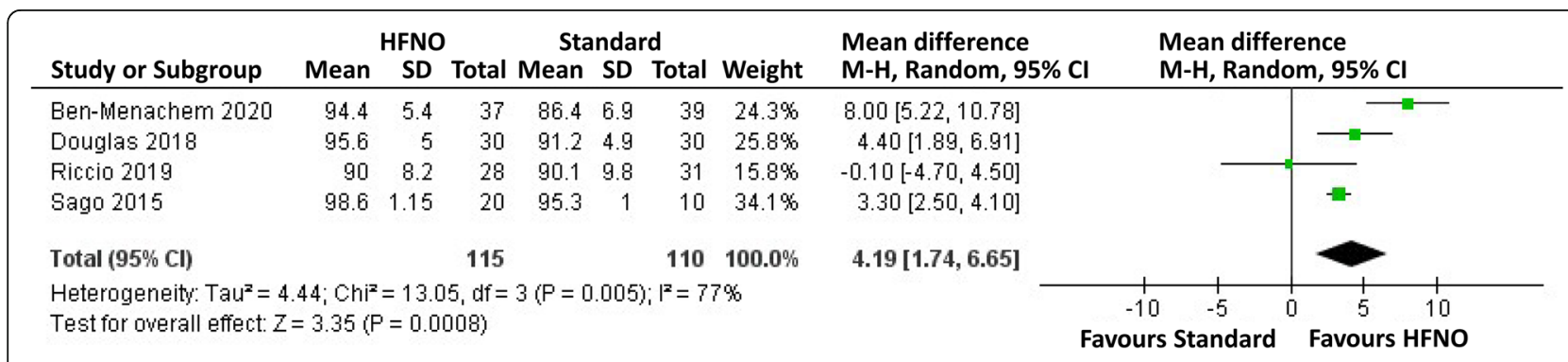

Fig. 3 Forest plot of the comparison of lowest $\mathrm{SpO}_{2}$ between HFNO and standard oxygen therapy groups 


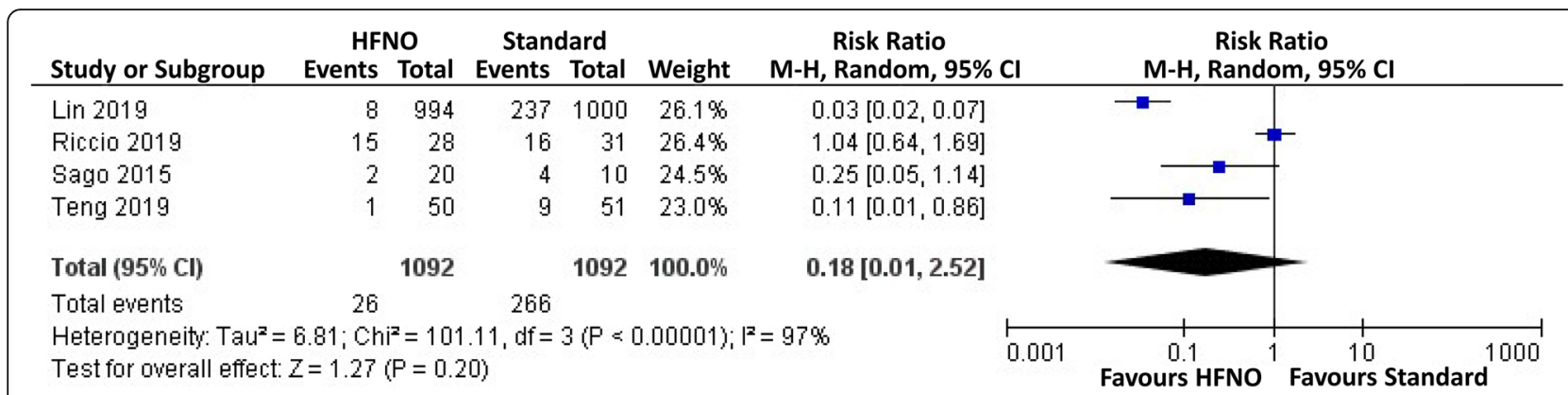

Fig. 4 Forest plot of the comparison of need for airway intervention between HFNO and standard oxygen therapy groups

using HFNO had higher minimum $\mathrm{SpO}_{2}$ than standard oxygen therapy. However, there was no significant difference in the risk of airway intervention, oxygen therapyrelated complications, patient, operator, or anesthetist satisfaction. Our findings support that HFNO may serve as a better oxygenation technique to prevent the occurrence of hypoxia compared to conventional oxygen therapy in patients undergoing sedation for medical procedures.

Several systematic reviews have studied the effect of HFNO in the perioperative period (Spence et al. 2020; Chaudhuri et al. 2020). Spence and colleagues demonstrated that in the intraoperative period, HFNO reduces the risk of $\mathrm{O}_{2}$ desaturation and increases minimum $\mathrm{O}_{2}$ saturation and safe apnea time compared with conventional oxygenation, consistent with our results (Spence et al. 2020). In contrast, Chaudhuri and co-workers focused on the peri-intubation period and found that HFNO is not associated with severe desaturation, serious complications, apneic time, length of intensive care unit stay, or overall survival (Chaudhuri et al. 2020). The authors analyzed severe desaturation defined as $\mathrm{SpO}_{2}<$ $80 \%$, which is likely to have a lower rate compared to our definition $\mathrm{SpO}_{2}<90 \%$ (Chaudhuri et al. 2020). In addition, their analyses mixed perioperative nonhypoxemic patients and critically ill hypoxemic patients (Chaudhuri et al. 2020). Underpowered statistics and heterogeneous populations may explain the nonsignificant difference in desaturation risk between HFNO and standard oxygen therapy.

Obesity is associated with increased sedation-related complications, including hypoxia (Kilic et al. 2019; Jirapinyo and Thompson 2016). Most trials in our analysis recruited patients with BMI $<28 \mathrm{~kg} / \mathrm{m}^{2}$, except for the study of Riccio and colleagues (Riccio et al. 2019). Our subgroup analyses indicated that the reduced desaturation risk and higher minimum $\mathrm{SpO}_{2}$ associated with HFNO were augmented in nonobese patients. Similarly, the intergroup difference in need for airway intervention was only significant in nonobese patients. Conversely, a recent clinical trial demonstrated that HFNO achieved a longer safe apnea time and higher minimum $\mathrm{SpO}_{2}$ compared to facemask oxygenation in patients with morbid obesity undergoing anesthesia induction (Wong et al. 2019). More studies are required to determine whether HFNO is effective in preventing desaturation in obese patients undergoing procedural sedation.

The depth of sedation may have an influence on respiratory-related complications (American Society of Anesthesiologists, Committee on Quality Management and Departmental Administration 2019). Deep sedation may exert a higher risk of hypoventilation, airway obstruction, and desaturation, particularly when propofol is used as the primary sedative (Sheahan and Mathews 2014). Our selected studies used different assessment tools for depth of sedation. Two trials maintained the patients at moderate sedation with Modified Observer's Assessment of Alertness/Sedation Scale (MOAA/S) equal to 4 and Ramsay Sedation Scale $>4$ (Douglas et al. 2018; Lin et al. 2019); one trial maintained the patients at moderate-to-deep sedation with Richmond AgitationSedation Scale of -3 to -4 (Riccio et al. 2019); two trials maintained deep sedation with bispectral index around 70 and MOAA/S < 2 (Teng et al. 2019; Sago et al. 2015). However, the available data were insufficient for subgroup analysis. Further research should evaluate the effect of varying depths of sedation on the effectiveness of HFNO in oxygenation and prevention of desaturation.

The use of higher $\mathrm{FiO}_{2}$ itself may reduce risk of desaturation in procedural sedation. A nasal cannula with an oxygen flow rate of 4 to $10 \mathrm{~L} / \mathrm{min}$ provides $\mathrm{FiO}_{2} 30$ to $35 \%$, and oxygen through bite block with a flow rate of $10 \mathrm{~L} / \mathrm{min}$ provides $\mathrm{FiO}_{2}$ approximately 35\% (Ting et al. 2012). In our analysis, only two trials used the same $\mathrm{FiO}_{2}$ in both groups (Riccio et al. 2019; Sago et al. 2015), and three trials used $\mathrm{FiO}_{2} 100 \%$ in the HFNO group (Douglas et al. 2018; Lin et al. 2019; Teng et al. 2019). The difference in applied $\mathrm{FiO}_{2}$ between groups may confound the effect of oxygenation techniques on desaturation risk. Nevertheless, HFNO may improve oxygen delivery by minimizing oxygen dilution and reducing dead space compared to conventional oxygen therapy regardless of $\mathrm{FiO}_{2}$ (Lee et al. 2016). 
Our study covered the procedures requiring sedation, including gastrointestinal endoscopy, bronchoscopy, and dental treatments. Although these procedures are typically performed outside the operating room, patients with the potential to convert to conventional surgery or general anesthesia may undergo these procedures in the operating room (Youn et al. 2015). In addition, operations undertaken with a varying level of sedation are also common in the operating room. The oxygenation strategy to prevent desaturation is of equal importance to these procedures and operations, especially in the field of airway management.

Our study has several limitations. First, some trials had a small sample size of 10 per treatment group (Sago et al. 2015). Second, it is difficult to conduct a metaanalysis for some outcomes due to insufficient data, such as oxygen therapy-related complications. Third, the satisfaction score was subjective and was likely to be biased as the participants were not blinded to assigned intervention. Fourth, the cost of HFNO is much higher than conventional oxygen therapy, but we did not analyze cost effectiveness (Eaton Turner and Jenks 2018). Fifth, there is considerable heterogeneity in the type and dosage of sedative agents and patients' baseline clinical conditions among the included trials. Finally, pediatric, hypoxemic, and extubated patients were excluded from the analysis. Therefore, our results are not applicable to these populations.

\section{Conclusions}

Our systematic review and meta-analysis demonstrated that HFNO may reduce the risk of desaturation and increase the lowest $\mathrm{SpO}_{2}$ in patients receiving sedation for medical procedures compared to standard oxygen therapy. HFNO can be considered as the choice of oxygen therapy in procedural sedation. Future studies should focus on high-risk patients, such as those with respiratory distress and morbid obesity.

\section{Abbreviations}

BMI: Body mass index; $\mathrm{Cl}$ : Confidence interval; $\mathrm{FiO}_{2}$ : Fraction of inspired oxygen; HFNO: High-flow nasal oxygenation; IQR: Interquartile range; MOAA/ S: Modified Observer's Assessment of Alertness/Sedation Scale;

RCTs: Randomized controlled trials; SD: Standard deviation; $\mathrm{SpO}_{2}$ : Peripheral oxygen saturation; WMD: Weighted mean difference

\section{Acknowledgements}

Not applicable

\section{Authors' contributions}

Conception and design: Jui-Tai Chen, Chun-Cheng Li, Ying-Hsuan Tai Development of methodology: Hsin-Yi Liu, Ka-Wai Tam, Jui-Tai Chen Data acquisition: Hsin-Yi Liu, Ka-Wai Tam, El-Wui Loh

Data analysis and interpretation: Hsin-Yi Liu, Ka-Wai Tam, El-Wui Loh, HsienCheng Kuo

Writing of the manuscript: Hsin-Yi Liu, Ka-Wai Tam, El-Wui Loh, Ying-Hsuan Tai

Review and/or revision of the manuscript: Wan-Chi Liu, Jui-Tai Chen, Yih-

Giun Cherng, Ying-Hsuan Tai
Approval of the final version: all authors

\section{Funding}

This work was supported by the grants from Shuang Ho Hospital (109|IT-02), Taipei Medical University, New Taipei City, Taiwan and Ministry of Science and Technology (MOST109-2314-B-038-024), Taipei, Taiwan.

Availability of data and materials

The materials are retrieved from published data.

\section{Declarations}

Ethics approval and consent to participate

Not applicable

\section{Consent for publication}

Not applicable

\section{Competing interests}

The authors declare that they have no competing interests.

\section{Author details}

'Department of Anesthesiology, Shuang Ho Hospital, Taipei Medical University, No. 291, Zhongzheng Rd., Zhonghe District, New Taipei City 23561, Taiwan. ${ }^{2}$ Department of Anesthesiology, School of Medicine, College of Medicine, Taipei Medical University, Taipei, Taiwan. ${ }^{3}$ Division of General Surgery, Department of Surgery, Shuang Ho Hospital, Taipei Medical University, New Taipei City, Taiwan. ${ }^{4}$ Department of Surgery, School of Medicine, College of Medicine, Taipei Medical University, Taipei, Taiwan. ${ }^{5}$ Cochrane Taiwan, Taipei Medical University, Taipei, Taiwan. ${ }^{6}$ Department of Dentistry, Shuang Ho Hospital, Taipei Medical University, New Taipei City, Taiwan. ${ }^{7}$ Graduate Institute of Clinical Medicine, College of Medicine, Taipei Medical University, Taipei, Taiwan.

Received: 8 February 2021 Accepted: 8 August 2021

Published online: 06 December 2021

\section{References}

American Society of Anesthesiologists, Committee on Quality Management and Departmental Administration, 2019. Continuum of depth of sedation: definition of general anesthesia and levels of sedation/analgesia. Available from: https://www.asahq.org/standards-and-guidelines/continuum-of-depthof-sedation-definition-of-general-anesthesia-and-levels-of-sedationanalgesia. Accessed June 3, 2021.

Amornyotin S. Sedation-related complications in gastrointestinal endoscopy. World J Gastrointest Endosc. 2013;5(11):527-33. https://doi.org/10.4253/wjge. v5.i11.527.

Ben-Menachem E, McKenzie J, O'Sullivan C, Havryk AP. High-flow nasal oxygen versus standard oxygen during flexible bronchoscopy in lung transplant patients: a randomized controlled trial. J Bronchology Interv Pulmonol. 2020; 27(4):259-65. https://doi.org/10.1097/LBR.0000000000000670.

Chaudhuri D, Granton D, Wang DX, Einav S, Helviz Y, Mauri T, et al. Moderate certainty evidence suggests the use of high-flow nasal cannula does not decrease hypoxia when compared with conventional oxygen therapy in the peri-intubation period: results of a systematic review and meta-analysis. Crit Care Med. 2020;48(4):571-8. https://doi.org/10.1097/CCM.0000000000004217.

DerSimonian R, Laird N. Meta-analysis in clinical trials. Control Clin Trials. 1986; 7(3):177-88. https://doi.org/10.1016/0197-2456(86)90046-2.

Douglas N, Ng I, Nazeem F, Lee K, Mezzavia P, Krieser R, et al. A randomised controlled trial comparing high-flow nasal oxygen with standard management for conscious sedation during bronchoscopy. Anaesthesia. 2018;73(2):169-76. https://doi.org/10.1111/anae.14156.

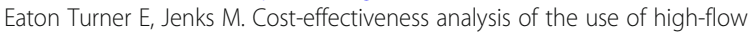
oxygen through nasal cannula in intensive care units in NHS England. Expert Rev Pharmacoecon Outcomes Res. 2018;18(3):331-7. https://doi.org/10.1 080/14737167.2018.1411804.

Gerstein NS, Young A, Schulman PM, Stecker EC, Jessel PM. Sedation in the electrophysiology laboratory: a multidisciplinary review. J Am Heart Assoc. 2016;5:e003629.

Helviz Y, Einav S. A systematic review of the high-flow nasal cannula for adult patients. Crit Care. 2018;22(1):71. https://doi.org/10.1186/s13054-018-1990-4. 
Higgins JP, Altman DG, Gøtzsche PC, Jüni P, Moher D, Oxman AD, et al. Cochrane Bias Methods Group; Cochrane Statistical Methods Group. The Cochrane Collaboration's tool for assessing risk of bias in randomised trials. BMJ. 2011; 343:d5928.

Jirapinyo P, Thompson CC. Sedation challenges: obesity and sleep apnea. Gastrointest Endosc Clin N Am. 2016;26(3):527-37. https://doi.org/10.1016/j. giec.2016.03.001

Kilic ET, Sayar S, Kahraman R, Ozdil K. The effects of obesity on sedation-related outcomes of advanced endoscopic procedures. North Clin Istanb. 2019;6(4): 321-6. https://doi.org/10.14744/nci.2019.93763.

Lee CC, Mankodi D, Shaharyar S, Ravindranathan S, Danckers M, Herscovici P, et al. High flow nasal cannula versus conventional oxygen therapy and noninvasive ventilation in adults with acute hypoxemic respiratory failure: a systematic review. Respir Med. 2016;121:100-8. https://doi.org/10.1016/j. rmed.2016.11.004

Lin Y, Zhang X, Li L, Wei M, Zhao B, Wang X, et al. High-flow nasal cannula oxygen therapy and hypoxia during gastroscopy with propofol sedation: a randomized multicenter clinical trial. Gastrointest Endosc. 2019;90(4):591-601. https://doi.org/10.1016/j.gie.2019.06.033.

Luo D, Wan X, Liu J, Tong T. Optimally estimating the sample mean from the sample size, median, mid-range, and/or mid-quartile range. Stat Methods Med Res. 2018;27(6):1785-805. https://doi.org/10.1177/0962280216669183.

Mason KP, Roback MG, Chrisp D, Sturzenbaum N, Freeman L, Gozal D, et al. Results from the adverse event sedation reporting tool: a global anthology of 7952 records derived from $>160,000$ procedural sedation encounters. J Clin Med. 2019;8(12):2087. https://doi.org/10.3390/jcm8122087.

Meining A, Semmler V, Kassem AM, Sander R, Frankenberger U, Burzin M, et al. The effect of sedation on the quality of upper gastrointestinal endoscopy: an investigator-blinded, randomized study comparing propofol with midazolam. Endoscopy. 2007;39(04):345-9. https://doi.org/10.1055/s-2006-945195.

Moher D, Liberati A, Tetzlaff J, Altman DG, PRISMA Group. Preferred reporting items for systematic reviews and meta-analyses: the PRISMA statement. J Clin Epidemiol. 2009;62(10):1006-12. https://doi.org/10.1016/j.jclinepi.2009.06.005.

Qadeer MA, Lopez AR, Dumot JA, Vargo JJ. Hypoxemia during moderate sedation for gastrointestinal endoscopy: causes and associations. Digestion. 2011;84(1):37-45. https://doi.org/10.1159/000321621

Riccio CA, Sarmiento S, Minhajuddin A, Nasir D, Fox AA. High-flow versus standard nasal cannula in morbidly obese patients during colonoscopy: a prospective, randomized clinical trial. J Clin Anesth. 2019;54:19-24. https:// doi.org/10.1016/j.jclinane.2018.10.026.

Sago T, Harano N, Chogyoji Y, Nunomaki M, Shiiba S, Watanabe S. A nasal highflow system prevents hypoxia in dental patients under intravenous sedation. J Oral Maxillofac Surg. 2015;73(6):1058-64. https://doi.org/10.1016/j.joms.2 014.12.020.

Sheahan CG, Mathews DM. Monitoring and delivery of sedation. Br J Anaesth. 2014;113(Suppl 2):ii37-47.

Shi J, Luo D, Weng H, Zeng XT, Lin L, Chu H, et al. Optimally estimating the sample standard deviation from the five-number summary. Res Synth Methods. 2020;11(5):641-54. https://doi.org/10.1002/jrsm.1429.

Shirota Y, Hirase Y, Suda T, Miyazawa M, Hodo Y, Wakabayashi T. More than half of hypoxemia cases occurred during the recovery period after completion of esophagogastroduodenoscopy with planned moderate sedation. Sci Rep. 2020;10(1):4312. https://doi.org/10.1038/s41 598-020-61120-0.

Spence EA, Rajaleelan W, Wong J, Chung F, Wong DT. The effectiveness of highflow nasal oxygen during the intraoperative period: a systematic review and meta-analysis. Anesth Analg. 2020;131(4):1102-10. https://doi.org/10.1213/A NE.0000000000005073.

Spoletini G, Alotaibi M, Blasi F, Hill NS. Heated humidified high-flow nasal oxygen in adults: mechanisms of action and clinical implications. Chest. 2015;148(1): 253-61. https://doi.org/10.1378/chest.14-2871.

Teng WN, Ting CK, Wang YT, Hou MC, Chang WK, Tsou MY, et al. High-flow nasal cannula and mandibular advancement bite block decrease hypoxic events during sedative esophagogastroduodenoscopy: a randomized clinical trial. Biomed Res Int. 2019;2019:4206795.

Ting CK, Orr JA, Yu L, Westenskow DR. Comparison of $\mathrm{FiO}_{2}$ of nasal cannulas, masks, and mouth bite block using in sedation patients during esophagogastroduodenoscopy: a bench study: ASA annual meeting; 2012.

Wehrmann T, Riphaus A. Sedation with propofol for interventional endoscopic procedures: a risk factor analysis. Scand J Gastroenterol. 2008;43(3):368-74. https://doi.org/10.1080/00365520701679181.
Wong DT, Dallaire A, Singh KP, Madhusudan P, Jackson T, Singh M, et al. Highflow nasal oxygen improves safe apnea time in morbidly obese patients undergoing general anesthesia: a randomized controlled trial. Anesth Analg. 2019;129(4):1130-6. https://doi.org/10.1213/ANE.0000000000003966.

Xiao Q, Yang Y, Zhou Y, Guo Y, Ao X, Han R, et al. Comparison of nasopharyngeal airway device and nasal oxygen tube in obese patients undergoing intravenous anesthesia for gastroscopy: a prospective and randomized study. Gastroenterol Res Pract. 2016;2016:2641257.

Youn AM, Ko YK, Kim YH. Anesthesia and sedation outside of the operating room. Korean J Anesthesiol. 2015;68(4):323-31. https://doi.org/10.4097/kjae.2 015.68.4.323.

\section{Publisher's Note}

Springer Nature remains neutral with regard to jurisdictional claims in published maps and institutional affiliations.
Ready to submit your research? Choose BMC and benefit from:

- fast, convenient online submission

- thorough peer review by experienced researchers in your field

- rapid publication on acceptance

- support for research data, including large and complex data types

- gold Open Access which fosters wider collaboration and increased citations

- maximum visibility for your research: over $100 \mathrm{M}$ website views per year

At $\mathrm{BMC}$, research is always in progress.

Learn more biomedcentral.com/submissions 